\title{
Filosofia e pandemia: uma lista de problemas
}

\author{
https://doi.org/10.21814/uminho.ed.23.6
}

\section{João Cardoso Rosas}

João Cardoso Rosas (ORCID: 0000-0003-3627-2414) é licenciado e mestre pela Universidade do Porto e doutorado pelo Instituto Universitário Europeu, sendo Professor Associado do Departamento de Filosofia e investigador do Centro de Ética, Política e Sociedade. Foi presidente da Associação Portuguesa de Ciência Política e da Sociedade Portuguesa de Filosofia. O seu trabalho, sempre no âmbito da Filosofia Política, tem incidido especialmente em questóes de justiça e direitos humanos. O seu livro mais recente é: (org.), História da Filosofia Política, Lisboa, Presença, 2020. 
Será que os filósofos têm algo de relevante a dizer sobre a pandemia que outras áreas académicas não podem ou não estão vocacionadas para dizer? Creio que a resposta a esta pergunta é inequivocamente positiva. As disciplinas científicas de base empírica, das Ciências da Vida à Matemática Aplicada e da Economia à Ciência Política, ou à História, têm certamente muito a investigar e a descobrir em torno da pandemia, das suas causas, efeitos e antecedentes longínquos. Mas a Filosofia pode e deve abordar muitas outras questôes, normativas e até existenciais, que a pandemia coloca. Porém, antes de detalhar a minha resposta e de ilustrá-la com alguns dos problemas mais significativos que, neste contexto, a Filosofia poderá endereçar de forma insubstituível, gostaria de explicar qual o tipo de formulaçóes filosóficas que devemos evitar - e que correspondem, ao que por vezes se chama «filosofia oracular».

Segundo a tradição da filosofia oracular caberia aos filósofos cultivar a Verdade que permanece, ou deve permanecer, escondida do comum dos mortais. A tradição oracular é muito antiga e não se pode negar que tem uma genealogia respeitável. Ela foi estabelecida por Platão, com a sua famosa Teoria das Formas ou Ideias, tal como explicada metaforicamente na Alegoria da Caverna. A maior parte de nós vive num mundo que julga real mas que não passa de um conjunto de sombras projetadas na parede de uma caverna pela luz de uma fogueira. A verdadeira realidade é composta pelas Ideias ou Formas puras que apenas os filósofos poderão chegar a «ver», mediante uma aturada e difícil dialética ascendente que os levará a sair da caverna em que todos nos encontramos à partida para a luz pura de um sol inteligível.

Esta teoria platónica é central para a compreensão de todo o pensamento ocidental, incluindo o que designamos por Ciência Moderna. No fundo, aquilo que todos fazemos nas universidades e instituições de investigação é seguir o conselho de Platão e tentar ver para além das evidências imediatas. Ou seja, tentamos encontrar a luz para além das sombras que nos rodeiam, formulando hipóteses e teorias contraintuitivas, afastando-nos da perceção imediata e ingénua do real para, mediante esse distanciamento metodológico, melhor o compreendermos. Não admira por isso que haja quem considere que o pensamento ocidental não é mais do que um conjunto de notas de rodapé à filosofia de Platão. 
Mas a teoria platónica das Ideias ou Formas é também tributária de perspetivas da Filosofia pré-socrática - sobretudo da Escola Eleática de Parménides - e, em última instância, das visóes iniciáticas da religião dos gregos. Alguns dos seus intérpretes levaram talvez demasiado a sério este aspeto iniciático e marcadamente oracular da teoria, procurando guardar para uma classe de indivíduos, à qual eles próprios invariavelmente pertencem, geralmente os filósofos, mas por vezes também um grupo de teólogos, ou de cientistas, o privilégio de acesso à Verdade e, a partir daí, uma espécie de direito natural a explicá-la aos outros, se assim o desejarem, e, claro está, a governar a sociedade de acordo com essa mesma Verdade.

A cultura mediática contemporânea não deixou de adotar esse tipo de tradição, adaptando-a ao contexto de uma sociedade de massas. Alguns filósofos - que na tradição francesa se designam por «maîtres à penser» - consideram seu dever compreender rapidamente o que outros não alcançam, interpretar o Zeitgeist, e lançar essa luz sobre o vulgo, mas geralmente transmitindo a impressão que não dizem tudo e guardam o melhor para si mesmos. Foi assim que vimos vários pensadores a produzir quase instantaneamente não apenas breves ensaios filosóficos, mas livros completos, para nos explicar a pandemia, o seu significado profundo e as suas consequências insondáveis para a maioria, quando essa pandemia estava ainda no seu início e rodeada das maiores incertezas.

O caso mais interessante - mas não de forma alguma o único - deste tipo de operação típica da filosofia oracular foi o do pensador italiano Giorgio Agamben, uma das figuras mais influentes da filosofia europeia contemporânea. Agamben reagiu prontamente ao alastrar da epidemia em Itália. No dia 26 de fevereiro publicou na plataforma da editora Quodlibet um texto em que lança dúvidas sobre a realidade factual da epidemia falando sobre «uma suposta pandemia» e considerando as medidas de emergência como «irracionais e totalmente infundadas». A suspeição levantada por Agamben, quando existiam já «zonas vermelhas» na Lombardia e se impunha uma ação decidida por parte do governo, está ancorada na sua filosofia e, mais especificamente, na ideia de que a governação atual tende a usar a ideia de «estado de emergência» como seu paradigma de atuação (uma ideia que surge da interpretação feita por Agamben da centralidade do «estado de exceção» no pensamento de Carl Schmitt). 
Agamben insiste na mesma linha argumentativa num outro artigo, também em Quodlibet.it, publicado no dia 11 de março. Segundo Agamben, algo semelhante ao que atualmente vivemos terá acontecido com a ameaça terrorista e o cancelamento ou limitação de liberdades na «guerra ao terrorismo». Face ao declínio desta «guerra» os governos inventaram outra, a «guerra ao vírus», de modo a poderem continuar a justificar a expansão dos seus poderes e a limitação das liberdades dos cidadãos. No quadro do combate ao terrorismo os cidadãos foram todos transformados em potenciais terroristas e tratados como tal. No contexto da «suposta» pandemia os cidadãos são potenciais contagiadores e por isso devem ser vigiados e mantidos à distância. Daí o favorecimento do teletrabalho, do ensino não presencial, com os campi esvaziados e o potencial contestatário das universidades devidamente controlado.

Não é difícil simpatizar com os receios de Agamben sobre as transformações políticas induzidas pela pandemia e voltaremos ao assunto mais adiante. É sem dúvida importante denunciar, como ele o faz, os usos perversos da linguagem - a «guerra» - a que recorre o discurso político no contexto pandémico. Mas o que verdadeiramente choca na sua intervenção, pelo menos para os menos habituados às filosofias oraculares, é a negação categórica das evidências empíricas: a epidemia não é real, mas «suposta». As medidas dos governos não visam salvar vidas, são apenas uma astúcia do poder. É sabido que o filósofo oracular nunca perde uma oportunidade para encontrar naquilo que observa a confirmação das suas teorias. Porque pensa que a governação atual tem como paradigma a criação de um «estado de emergência» permanente, Agamben reinterpreta, ou sobreinterpreta, factos que à partida não pareciam contestáveis. A realidade é forçada para dentro da teoria, por assim dizer. E se alguém coloca em causa o que diz o filósofo oracular, em nome das evidências, ele poderá sempre aduzir que o comum dos mortais não vê tão longe quanto ele.

Um outro filósofo italiano, menos dado a teorias conspirativas ou à sobreinterpretação dos factos, Paolo Flores d'Arcais, respondeu à letra a Agamben na revista Micromega no dia 16 de março, recordando que a o problema do contágio não é uma invenção do governo ou dos média para militarizar o país. Se cada pessoa pode transmitir a infeção isso deve-se à existência do vírus e ao modo da sua transmissão, não a invenções de natureza política. A epidemia não é uma conspiração do poder. E remata: 
«É necessário que a filosofia inaugure uma época em que a sua estrela polar regresse ao amor do conhecimento/sabedoria, e o conhecimento é o das ciências, não o das para- ou pós- elocubraçôes teológicas». Em suma: Agamben e outros filósofos fariam melhor em pensar, tendo em conta os dados empíricos e as contribuições das ciências, em vez de se refugiarem nos seus oráculos e na sua pseudo-relação com uma Verdade vedada a todos os demais.

No dia 17 de março, Agamben voltou à carga para afirmar, face ao confinamento e à paralisia do país, que «a nossa sociedade já não acredita em nada que não seja a vida nua» (sic). O que quer aqui dizer, no seu vocabulário próprio, é que as sociedades contemporâneas já só acreditam na preservação da vida biológica e na sua salvação a todo o custo. Note-se que, neste artigo, o argumento de Agamben muda. Já não se trata aqui de negar a realidade da pandemia, algo que em fevereiro poderia fazer duvidar os incautos mas que em março soaria a simples delírio, mas antes de dizer que a insistência no seu combate, para além de instaurar o já referido «estado de emergência» permanente, mostra a degradação das sociedades contemporâneas ao privilegiar acima de tudo a preservação da vida. Claro que o leitor poderá pensar que essa preservação da vida é um valor positivo e corresponde mesmo a um avanço moral do mundo contemporâneo. Mas, para o filósofo oracular, essa afirmação está demasiado próxima do senso comum e não é capaz de captar a profunda crítica social que o filósofo desenvolve no seu jargão próprio.

Note-se que o «caso Agamben», como é agora conhecido em Itália, é apenas um exemplo daquilo que chamei «filosofia oracular» no tratamento da pandemia. $\mathrm{Na}$ coletânea dos seus textos publicada em espanhol e acima referenciada, há algumas contribuiçôes muito relevantes - por exemplo a de Byung-Chul Han - mas há também outras que, sem terem o impacto social dos textos de Agamben, levam o delírio especulativo ainda mais longe do que o pensador italiano. Por exemplo, o texto de Maria Galindo consegue ultrapassar, aparentemente sem remorsos, o plano da razoabilidade e da própria racionalidade ao defender que a nossa única alternativa face às políticas estatais é «Cultivar o contágio, expormo-nos ao contágio e desobedecer para sobreviver». O presidente Jair Bolsonaro do Brasil, politicamente situado nos antípodas de Maria Galindo, não diria melhor. 
Mas creio que o que foi exposto é suficiente para ilustrar aquilo que considero o tipo de respostas filosóficas a evitar. Convém agora explicitar as razões pelas quais julgo que, ainda assim, a Filosofia tem ou pode ter algo de muito relevante a acrescentar sobre a pandemia. Limitar-me-ei aos temas com os quais estou mais familiarizado, de Ética e Filosofia Política, deixando de fora aquilo que outras subdisciplinas filosóficas - a Estética, a Epistemologia, a Filosofia da Mente, a Ontologia, etc. - terão com certeza a adir.

Pois bem, para os filósofos não-oraculares a pandemia constitui aquilo a que se costuma chamar uma «situação-limite», um termo cunhado por Karl Jaspers, mas que usamos aqui de forma livre. Uma situação-limite é um contexto disruptivo, no qual está em causa a nossa vida e que conduz muitas vezes ao sofrimento. Por isso, uma situação-limite, seja ela vivida em termos pessoais (e.g., a notícia de uma doença incurável), ou experienciada de forma mais alargada e partilhada pela comunidade (como a pandemia), confronta e coloca em questão os nossos valores e visóes do mundo e da vida.

Isto é, uma situação-limite, se tivermos boa-fé e abertura intelectual, não é mais uma oportunidade para confirmar as nossas teorias e mostrar como elas nos permitem compreender o presente e antecipar o futuro. Pelo contrário, trata-se de um contexto que coloca à prova, como nenhum outro, todas essas teorias e horizontes de expectativas, colocando novos problemas ou reformulando problemas antigos a uma nova luz. O que importa nesta situação é verificar, de forma aberta e intelectualmente honesta, se essas teorias resistem aos factos e às interpretações que deles podemos fazer racionalmente ou se, pelo contrário, a razão e os dados empíricos e das diversas ciências recomendam que as nossas teorias e expectativas sejam substituídas por outras, desejavelmente mais robustas, aperfeiçoando ou criando novos conceitos e interpretaçóes.

Sem aspirar a qualquer exaustividade, elencamos a partir de agora alguns problemas éticos e políticos que surgem da confrontação entre as nossas teorias ou horizontes de expectativas, por um lado, e a realidade observada ou vivenciada no quadro da pandemia em curso. Trata-se apenas de fazer uma espécie de lista de problemas a tratar de um ponto de vista filosófico, alguns dos quais começaram já a ser endereçados por alguns autores. 
O primeiro desses problemas tem a ver com o medo que a pandemia provoca. Enquanto sociedade, raramente somos confrontados com uma situação de medo generalizado, correndo o risco de degenerar em pânico. Mas foi isso mesmo que se passou logo nos momentos iniciais da pandemia - e que pode voltar a acontecer se as condições se agravarem. Note-se que a obrigação de confinamento estabelecida pelos governos veio apaziguar a situação. Mas os próprios cidadãos já tinham iniciado esse confinamento, pelo menos aqueles que podiam fazê-lo, antes mesmo das medidas legislativas nesse sentido.

A Filosofia Política tem uma larga prática na reflexão sobre o medo e sobre o papel que ele desempenha na existência de sociedades organizadas e no exercício do poder político. Thomas Hobbes, o fundador do pensamento político moderno, considerava que o medo é mesmo a nossa paixão fundamental. Na ausência de um estado politicamente organizado prevalece o medo da morte e a vida dos homens tende a ser difícil e breve. O medo, juntamente com a esperança de uma vida mais confortável, é o grande impulsionador da aceitação do poder do estado por parte dos indivíduos. Mas Hobbes também compreendeu que esse medo fica, por assim dizer, latente mesmo num estado político. É também o medo face ao poder soberano, seja ele assumido por apenas um homem ou por um parlamento, que permite a manutenção da ordem social regulada.

Veja-se o papel que o medo continua a desempenhar à medida que as nossas sociedades passaram da fase de confinamento para um desconfinamento progressivo. Muitos, geralmente jovens, tentam enfrentar o seu medo profundo com bravatas de exposição ao vírus, especialmente na companhia de grandes grupos e do impulso mimético que eles incentivam. Outros, usualmente mais maduros, racionalizam o seu medo e mantêm a «distância física», muitas vezes - e significativamente - apelidada de «distanciamento social». A sociedade política é o que nos protege, mas continua a ser também, no âmago da sua precariedade, algo que nos ameaça.

A pandemia, tal como acontece geralmente com catástrofes naturais, ou com a guerra, especialmente se for guerra civil, veio, pois, recordar-nos a fragilidade das sociedades politicamente organizadas e o modo como elas podem rapidamente, se não existir uma condução política da situação, cair na anomia. Com certeza que nos próximos tempos os filósofos voltarão a este tipo de reflexão sobre o papel social e político do 
medo, mas também o de outras paixóes que o contrariam (a generosidade, o altruísmo), sobre a possibilidade sempre latente do crescimento da desordem social e a sua relação com a ação e a estrutura do poder político.

Um outro problema, muito específico, colocou-se cedo e com especial acuidade em Itália, depois também em Espanha. Trata-se de saber, de um ponto de vista ético, como distribuir cuidados de saúde numa situação de elevada procura e grande escassez de recursos face a essa procura. A intuição e a prática médica dizem-nos que devemos fazer tudo o que for possível e razoável para salvar doentes. Por isso montámos ao longo do século XX sistemas de saúde com cobertura universal, sobretudo na Europa. Mas como fazer quando esses sistemas têm claramente mais doentes para tratar do que os recursos disponíveis e, portanto, temos de decidir quem tratar e quem deixar morrer?

O critério mais aconselhado na literatura Ética é o do número de anos de vida com qualidade que se projeta para cada um dos indivíduos em causa. Por isso mesmo é que, quando temos de escolher entre salvar uma criança saudável ou alguém com muita idade ou que morreria em breve de outra doença, a escolha se impóe. Note-se que este problema é particularmente difícil para o pessoal de saúde porque se coloca aí a um nível individual e face à presença física das pessoas, do seu rosto e do seu sofrimento. Porém, numa escala diferente, é o tipo de escolha que se faz em políticas públicas entre, por exemplo, utilizar determinados recursos em cuidados de saúde ou em outro tipo de políticas sociais (ou outras, como por exemplo na defesa ou na cultura). Isso também tem um custo em termos de vidas humanas, mas como são vidas humanas estatísticas e o decisor político não está diante das vítimas, o problema não parece tão grave - e, de um certo ponto de vista, não o é realmente.

Talvez devamos reconhecer que este critério operativo para escolher entre vidas humanas, sendo de natureza ética, é também um critério consequencialista. Isso significa que apenas tem em conta os resultados ou consequências da nossa ação e não princípios independentes dessas consequências. Por isso não pode ser considerado justo. A justiça, ao contrário dos critérios consequencialistas, tem um cariz absoluto e afirma direitos e inviabilidades pessoais - a dignidade humana - que não são nunca, nem mesmo num momento de crise e necessidade premente de decisão, suscetíveis 
de ser cancelados ou relativizados. Ou seja, nunca é justo sacrificar pessoas para salvar outras.

No entanto, a questão da justificação última deste tipo de solução para o racionamento de cuidados de saúde é ela própria alvo de debate ao nível daquilo a que costumamos chamar a Ética Normativa, por oposição à Ética Aplicada. Mesmo no pouco desenvolvido debate português encontramos contribuições em sentidos contrários. Numa delas considera-se que este tipo de decisão de racionamento só pode mesmo ser justificada em termos consequencialistas, como acima se observou, já que não pode ter em conta o valor absoluto da dignidade humana. Noutra contribuição, pelo contrário, considera-se que podemos justificar esse racionamento recorrendo também a uma ética kantiana de valores absolutos. Não poderei alargar-me aqui sobre este problema, que constitui mais uma questão para os filósofos académicos do que para o público em geral. Mas ele mostra bem como a pandemia se constitui como situação-limite que coloca à prova as nossas teorias mais fundamentais.

Um problema que tem sido correntemente levantado relaciona-se com a origem do novo coronavírus. O facto de a transmissão para humanos se ter dado, ainda que acidentalmente, num mercado onde se transacionavam espécies animais selvagens, coloca no centro do problema da origem a relação entre o homem e a natureza. Há muito que as diversas correntes filosóficas da Ética Animal e da Ética Ambiental procuram criticar a relação de exploração e manipulação que existe em relação às espécies selvagens. Neste aspeto, a pandemia vem confrontar, de forma particularmente clara, as visóes antropocêntricas prevalecentes e que consideram, mesmo quando apresentam preocupaçóes ambientais relevantes, que a natureza, incluindo os animais não humanos, são apenas um recurso ao serviço da espécie humana. Ora, a origem da pandemia nesta visão de «recursos» parece confrontar o antropocentrismo prevalecente mesmo nas políticas ambientais e, como tal, abrir um maior espaço para as éticas animais e ecocêntricas que se têm vindo a afirmar.

Muitos têm ligado a pandemia a uma crise ecológica mais profunda, que inclui o aquecimento global e as alterações climáticas. Mas será talvez de evitar cair na tentação dos diagnósticos oraculares que tendem a considerar que esta pandemia, ou as epidemias de coronavírus, são uma espécie de «vingança» da natureza face à intervenção 
humana e à tão anunciada entrada na era do Antropocénico. Como alternativa reflexiva, o filósofo português que mais e melhor tem pensado a temática ambiental, Viriato Soromenho-Marques, coloca esta questão em perspetiva e procura relacionar a catástrofe pandémica e ambiental em curso com a ideologia moderna do progresso e dominação da natureza. Segundo o autor, a desordem política em que vivemos e os interesses das classes mais privilegiadas parecem anunciar que as más políticas do passado, tributárias da ideologia moderna, serão continuadas no pós-pandemia.

Uma outra questão, de natureza ética e política, tem a ver com o uso de tecnologias para a vigilância dos cidadãos e o controle da pandemia. A existência de novas tecnologias de vigilância e monitorização dos indivíduos coloca inúmeros problemas ao modo como concebemos a nossa relação com o estado e, especificamente, como interpretamos as liberdades fundamentais que as democracias procuram estabelecer e preservar. Todos sabemos que este problema não é novo e começou a ganhar os seus contornos atuais depois de 2001, com a chamada «guerra ao terrorismo». Foi nesse contexto que se usou e desenvolveu um maior conjunto de tecnologias com o objetivo de garantir a segurança, mas também com a consequência de uma muito maior intromissão na vida dos cidadãos e no controle dos seus movimentos.

Existe uma vasta literatura filosófica sobre o assunto, assim como uma reflexão de fundo sobre o conceito de liberdade na filosofia contemporânea, associada a autores como Isaiah Berlin, Quentin Skinner, Philip Pettit, etc. Mas os instrumentos atuais são cada vez mais aperfeiçoados, desde as tecnologias de vigilância urbana ao controlo dos movimentos de pagamentos eletrónicos e aos muito comentados programas de contact-tracing para telemóveis. Esta realidade deverá reavivar a reflexão filosófica, incidindo não apenas nas consequências mais óbvias para o controle da vida privada dos cidadãos, mas também nos conceitos de liberdade e privacidade nos quais geralmente confiamos, pelo menos no mundo ocidental.

Como refere provocatoriamente Byung-Chul Han, as sociedades asiáticas, pensando aqui sobretudo nos contextos confucionistas, têm um entendimento menos individualista das liberdades, que compatibilizam com os deveres face à comunidade e, por isso, estarão melhor preparadas para combater as pandemias do que as suas congéneres ocidentais. No entanto, não podemos também ser ingénuos neste ponto e 
devemos refletir sobre se o combate à pandemia com recurso a novas tecnologias não estará efetivamente a coartar as liberdades individuais, independentemente do modo como as possamos interpretar e conceber.

Ainda no domínio da reflexão sobre a tecnologia, é de salientar a importância crescente das aplicações que tornam possível desempenhar à distância as tarefas que antes considerávamos apenas in propria persona. A substituição do presencial pelo «à distância» ocorreu a uma velocidade nunca antes vista no domínio do trabalho, do comércio, dos cuidados de saúde (consultas médicas), da investigação e do ensino.

Estas transformações colocam em causa as relações interpessoais e a sua vivência subjetiva, mas também a própria convivência social e as suas implicações políticas. Ao nível do ensino e da investigação universitária, o adiamento ou a evitação das atividades presenciais, muitas vezes «normalizados» por teorias que advogam as vantagens deste tipo de mediação, póem em causa a própria ideia de universidade como locus, mas também topos, de interação, de construção participada do conhecimento e de crítica social.

As questões relacionadas com a tecnologia conduzem a uma outra, mais genérica: a do eventual abuso do «estado de emergência», colocado, como vimos, por Agamben, assim como por muitos outros. Este tema é obviamente relevante quando visto com respeito pelos dados empíricos e não, como entre os filósofos oraculares, como tese geral e irrefutável (apenas suscetível de confirmação). Os estados de exceção constitucionalmente previstos, seja qual for a sua designação (estado de emergência, estado de sítio, noutros países também estado de alerta, estado de calamidade, etc.) não têm de ser vistos como forma de minar a Constituição, ou como a revelação de que, no fundo, a Constituição não é democrática, mas antes como mecanismos internos que permitem salvaguardar a democracia em situações-limite. A Filosofia do Constitucionalismo Democrático nunca foi contrária a este tipo de mecanismos e nunca considerou, ao contrário de autores como Carl Schmitt e os seus seguidores contemporâneos, que o estado de emergência fosse a essência da Constituição, o seu alfa e o seu ómega. Essa é a teoria dos inimigos do Constitucionalismo Democrático, como Carl Schmitt, não a dos seus amigos. No entanto, a declaração da excecionalidade constitucional pode ser e tem sido utilizada no contexto da pandemia para reforçar de forma mais estrutural poderes não democráticos, como tem acontecido em alguns países, incluindo na União Europeia (e.g., Hungria). 
No contexto histórico em que vivemos, este desafio tem a ver com a concorrência global entre democracia e autocracia. Como nos ensina a Ciência Política, o movimento de expansão democrática iniciado em Portugal em abril de 1974 deu origem a uma vaga de democratização que continuou imparável até ao final do século XX (estendendo-se à Europa do sul, ao leste com a queda do Muro de Berlim, e um pouco por todo o mundo). Mas uma contra vaga democrática foi-se formando desde então, particularmente após o 11 de setembro de 2001 . O cenário atual está já longe do triunfalismo democrático dos anos 90 e mostra uma disputa internacional entre os modelos democráticos, por um lado, e os modelos autocráticos como o chinês, por outro lado. Além disso, muitas democracias estão agora em crise interna, precisamente sob a pressão dos populismos que, nascendo em contexto democrático, tendem a arrastar essas democracias para o lado autocrático, particularmente onde as instituições democráticas são mais recentes ou menos sólidas (cf. Polónia, Brasil, etc.).

A pandemia vem agravar esta concorrência entre as democracias constitucionais e os modelos alternativos na atualidade, surgidos externamente ou internamente a essas mesmas democracias (e muitas vezes de facto coligados, como se pode ver pela relação próxima entre líderes populistas nas democracias e líderes autocráticos, como Vladimir Putin na Rússia). Os regimes autocráticos, com o chinês à cabeça, posicionam-se para mostrar a sua superioridade no combate à pandemia, mediante o controle da informação e dos próprios cidadãos, com a fácil supressão de liberdades individuais, nos casos em que elas subsistiam ainda. As democracias constitucionais, tendo maior dificuldade ou mesmo desinteresse no controle da informação e na suspensão, ainda que temporária e constitucionalmente prevista, das liberdades fundamentais dos cidadãos, parecem por vezes estar a perder terreno, a assim também o seu prestígio e capacidade de atração global, face aos modelos não democráticos. O desafio aqui é simultaneamente prático e teórico. Consiste ele em mostrar que os regimes democráticos têm os meios e a vontade para serem tão bem-sucedidos, ou mais bem-sucedidos, do que os regimes não democráticos no combate à pandemia.

Note-se, a título de analogia, que durante muitos anos predominou na Teoria Política a tese segundo a qual a superioridade reputacional das democracias estava assegurada devido ao seu sucesso económico e social. Ou seja, a legitimação pelos outputs, 
ou resultados, que elas produziam seria suficiente para mostrar a sua superioridade face aos regimes não democráticos. Mas o modelo de desenvolvimento que se formou na Ásia, sobretudo na China, desmentiu esta suposta superioridade democrática. Seria trágico para as democracias que elas não soubessem agora, na prática e na teoria, mostrar que estão à altura da luta contra a pandemia e dispóem de mecanismos de gestão da informação, inovação científica e tecnológica e governabilidade que apresentam assinaláveis vantagens em relação aos modelos antidemocráticos.

Ora, os principais recursos intelectuais e normativos de que dispomos para defender a democracia constitucional face às ameaças autocráticas, venham elas das grandes potências no sistema internacional, ou das lutas políticas internas no seio das democracias, são os que podemos encontrar na tradição da Filosofia Política. Mas sejamos claros: parte dessa tradição é claramente adversa à democracia e ao valor da igualdade política que lhe subjaz. No contexto contemporâneo, o ataque e a suspeição face à democracia constitucional estende-se desde a maior parte das correntes marxistas, à esquerda, ao pensamento da direita reacionária ou mesmo às simpatias de muitos em relação ao fascismo (e.g. «o caso Heidegger»). No entanto, os recursos normativos para pensar, com total abertura e honestidade intelectual, as vantagens dos regimes constitucionais-democráticos face aos populismos autoritários e aos regimes autocráticos são imensas. Incluem as tradições do pensamento liberal e do pensamento democrático, extremamente diversas, de Locke a Rousseau e de Tocqueville a Stuart Mill, entre tantos outros. Mas também as contribuições contemporâneas, de Rawls, Dworkin, Walzer, etc. É toda esta herança intelectual que está em jogo e a sua capacidade para afirmar os valores dos direitos fundamentais e dos quesitos democráticos que os acompanham fica agora à prova.

Um outro desafio que a pandemia coloca ao pensamento democrático é o do papel dos especialistas no processo de tomada de decisóes. As filosofias oraculares tendem a considerar, desde Platão, que cabe aos filósofos ou outros especialistas dizer aos decisores políticos o que fazer. Essa atitude é ainda hoje muito prevalecente, entre filósofos e cientistas. A ideia geral é a de que, se algo corre mal por exemplo no combate à pandemia, isso deve-se ao facto de os decisores políticos não terem ouvido ou dado suficiente atenção à opinião científica especializada. A esta visão 
epistocrática cabe-nos opor uma epistemologia mais democrática e aberta à opinião dos não especialistas.

É com certeza verdade que a opinião dos especialistas, particularmente em sociedades complexas e tecnologicamente avançadas, é da maior importância. O desprezo por essa opinião, que se verifica muitas vezes na atualidade entre os políticos populistas, só pode causar dano às populações. No entanto, a arrogância dos experts é também nociva. Cabe aos políticos sopesar as diferentes considerações dos especialistas com a opinião pública, evitando analisar os problemas a partir de um ângulo único. Além disso, pelo menos em democracia, os políticos têm a legitimidade para decidir, o que não assiste aos experts. A insistência destes numa espécie de política científica ou tecnologicamente conduzida é mais uma versão do que por vezes se chama TINA (《There Is No Alternative»). No entanto, para o filósofo político, e ainda mais para o filósofo da democracia, as alternativas existem sempre e trata-se de compará-las não só em termos de cálculo custo-benefício, mas também em função dos valores alternativos que elas atualizam ou promovem.

Com a crescente perceção dos problemas económicos provocados pela pandemia e pelo combate à pandemia, surge com crescente acuidade a questão dos efeitos assimétricos da crise em função das desigualdades sociais pré-existentes. As divisões sociais existentes nas nossas sociedades, particularmente nas mais desiguais do ponto de vista da distribuição do rendimento e da riqueza, muitas vezes sobrepostas com outro tipo de desigualdades raciais, étnicas, de género, etc., fazem com que os efeitos da crise sejam sentidos de forma muito diferenciada e não de modo igual e transversal à sociedade.

Nada disso é surpreendente para a Filosofia Política contemporânea. Enquanto uma boa parte da tradição da Filosofia Política se ocupava sobretudo das questôes do estado e do poder político, da legitimidade e da democracia, o pensamento contemporâneo dá especial relevo à reflexão sobre a justiça, incluindo a distribuição justa de bens materiais (como o rendimento e a riqueza), mas também outros aparentemente imateriais, como as liberdades, as oportunidades e o reconhecimento positivo. Sobretudo através das contribuições de John Rawls e muitos outros que lhe sucederam (Amartya Sen, por exemplo), a Filosofia Política contemporânea sempre se preocupou em teorizar e oferecer soluções normativamente justificadas e politicamente exequíveis em 
democracia para os desequilíbrios sociais que minam a coesão das sociedades, o apoio popular que a sua organização política suscita e a sua estabilidade ao longo do tempo.

Com a pandemia, será necessário voltar à reflexão sobre a justiça e incidir especialmente nas questôes dos cuidados de saúde, do acesso aos cuidados básicos e também especializados em momentos «normais», antes e depois de crises pandémicas ou outras eà decisiva influência desses fatores - juntamente com o acesso à educação e formação - para a reforma social no sentido de uma melhor igualdade de oportunidades, distribuição de rendimentos e reconhecimento mútuo entre os cidadãos. Um outro aspeto específico da reflexão contemporânea sobre a justiça que terá de ser reavaliado é o da justiça em relação aos mais velhos e da justiça intergeracional (em relação às próximas gerações), face aos problemas e ressentimentos acima referidos no racionamento de cuidados de saúde e à previsibilidade de mais pandemias no nosso futuro globalizado.

A pandemia tem sido uma oportunidade para os defensores filosóficos do chamado Rendimento Básico Incondicional (RBI) reafirmarem a sua posição. Num contexto em que muitos cidadãos cairão em grande insegurança económica, a ideia de ser o estado a depositar diretamente nas suas mãos um rendimento suficiente para a vida, para todos e sem necessidades burocráticas de testes às condiçóes em que vivem (uma vez que todos os maiores de idade são elegíveis), surgiu como apelativa. Mas note-se que a argumentação filosófica a favor do RBI insiste sobretudo no seu papel para potenciar a liberdade dos indivíduos em sociedades altamente tecnológicas nas quais, segundo algumas previsóes, o trabalho tenderá a ser cada vez mais escasso e não acessível a todos. A pandemia é apenas mais uma oportunidade para complementar este argumento normativo básico com a ideia de que o RBI corresponde também a necessidades sociais prementes.

Uma crise também pré-existente a esta pandemia é a dos refugiados e migrantes económicos que tem pressionado não apenas a Europa, mas também várias outras partes do mundo. As crises de saúde e económicas que se avizinham nas regióes mais pobres do globo farão certamente eclodir novos movimentos de pessoas à procura de segurança física e económica. A Ética e a Filosofia Política têm desde há anos desenvolvido uma ampla reflexão sobre o assunto, protagonizada por alguns dos autores mais importantes, como David Miller ou Joseph Carens. Em contexto pandémico, a questão 
da permeabilidade das fronteiras, da sua maior abertura ou fechamento, assim como da capacidade das sociedades de acolhimento para a integração dos novos migrantes estará na ordem do dia. A avaliar pela produção teórica já disponível, as opiniốes continuarão a dividir-se entre os que preferem soluçóes mais abertas e cosmopolitas e os que favorecem a ideia de que «os bons muros fazem os bons vizinhos». Estou certo que outras questôes surgirão e que a Filosofia terá os recursos intelectuais para, senão resolvê-las, pelo menos clarificar as alternativas existentes.

O problema dos refugiados e migrantes ilustra bem um paradoxo fundamental do nosso tempo: os grandes problemas que enfrentamos, desde as crises migratórias à pobreza global, das catástrofes ambientais às crises pandémicas, são por definição globais, mas o combate a esses problemas parece ser cada vez mais local, numa fase de desglobalização do sistema internacional e de retraimento do espaço e da própria temporalidade vivida. Nunca na história uma pandemia foi tão global: pelo modo como se espalhou, pelas notícias que todos recebemos sobre ela, pelas estratégias de combate por parte dos governos, pela antecipação das suas repercussões futuras. Mas nada disso tem obstado a uma perceção meramente local e imediata dos problemas, à sua inserção nas clivagens políticas nacionais, às dificuldades da cooperação internacional no combate à doença e na procura de medicamentos e vacinas.

Para terminar, creio ser importante referir que a Filosofia tem também uma dimensão existencial relevante, vocacionada para enfrentar na primeira pessoa as grandes interrogações sobre a vida, a morte, o nosso destino individual e coletivo. A Filosofia, segundo a máxima ciceroniana de Montaigne, consiste em «aprender a morrer». Desde as grandes escolas filosófica das Antiguidade tardia, como o estoicismo e o epicurismo, ao existencialismo contemporâneo de autores como Camus e Sartre, passando por muitos outros, a Filosofia pode ser um bálsamo para tempos difíceis ou, pelo contrário, um acordar das consciências adormecidas pelo efeito anestesiante da quotidianidade. Esta dimensão da Filosofia, indo para além das áreas da Ética e Política que aqui me propus tratar, será com certeza central nos próximos tempos, durante e após a pandemia. Cada um de nós terá de aprender e reaprender a lidar individualmente e não apenas coletivamente com a perda, com a angústia - enfim, com o medo da morte, mas também com a esperança numa vida melhor. 


\section{REFERÊNCIAS BIBLIOGRÁFICAS}

Agamben, Giorgio et alt. (2020). Sopa de Wuban: Pensamiento Contemporáneo en Tiempos de Pandemias. Consultado em: http://tiempodecrisis.org/wp-content/uploads/2020/03/Sopa-de-WuhanASPO.pdf?fbclid=IwAR386959-_q7FG9ZCeGsEFSxGBOerZNNMf3s1hmLn8nYjcieT4QA-yyx6zE.

Campos, André. (2020). A filosofia política perante a COVID-19. Observador. Consulado em: https:// observador.pt/opiniao/a-filosofia-politica-perante-a-COVID-19/.

Cortinhas, Sérgio. (2020). Por favor não deixem morrer a minha mãe. Público. Consultado em: https://www. publico.pt/2020/04/30/p3/cronica/favor-nao-deixem-morrer-mae-1912648.

Critchley, Simon. (2020), To Philosophize Is to Learn How to Die. New York Times. Consultado em: https:// www.nytimes.com/2020/04/11/opinion/COVID-philosophy-anxiety-death.html.

Di Cesare, Donatella. (2020). Virus Soberano? A Asfixia Capitalista. Lisboa: Ediçóes 70.

Faria, Domingos. (2020). Um dilema ético gerado pela COVID-19. Público. Consultado em: https://www. publico.pt/2020/04/05/p3/cronica/dilema-etico-gerado-COVID19-1909773.

Flores D’Arcais, Paolo. (2020). Filosofia e vírus: le farneticazioni di Giorgio Agamben. In Micromega. Consultado em: http://temi.repubblica.it/micromega-online/filosofia-e-virus-le-farneticazioni-di-giorgioagamben/.

Galindo, Maria. (2020). Desobediencia, por tu culpa voy a sobrevivir. In Agamben et.alt. Sopa de Wuban. cit.

Gil, José. (2020a). O Medo. Público. Consultado em: https://www.publico.pt/2020/03/15/sociedade/ensaio/ medo-1907861.

Gil, José. (2020b). A crise da subjetividade. Público. Consultado em: https://www.publico.pt/2020/04/23/ opiniao/opiniao/crise-subjectividade-1912428.

Han, Byung-Chul. (2020). La emergência viral y el mundo de mañana. In Agamben et. alt. Sopa de Wuhan. cit. Lévy, Bernard-Henri (2020). Este Virus que nos Enlonquece. Lisboa: Guerra e Paz.

Merrill, Roberto e Standing, Guy. (2020). O coronavírus e o Rendimento Básico Incondicional. Público. Consultado em: https://www.publico.pt/2020/03/29/economia/opiniao/coronavirus-rendimento-basicoincondicional-1908674.

Patrão Neves, Maria do Céu. (2020). Como escolher quem salvar? "A seleção de doentes não é exclusiva do tempo de crise" [Entrevista a Bárbara Reis]. Público. Consultado em: https:/www.publico.pt/2020/03/25/ ciencia/entrevista/escolher-salvar-seleccao-doentes-nao-exclusiva-tempos-crise-1909293.

Reis, Bárbara. (2020a). Na pandemia não há fuga possível: a Filosofia pode ajudar? Público. Consultado em: https://www.publico.pt/2020/03/29/sociedade/noticia/pandemia-nao-ha-fuga-possivel-filosofiaajudar-1909923. 
Reis, Bárbara. (2020b). O preço a pagar é sermos mais vigiados? Público. Consultado em: https://www.publico. pt/2020/04/12/sociedade/noticia/preco-pagar-sermos-vigiados-1911651.

Soromenho-Marques, Viriato. (2020). Quando Teseu se rendeu ao Minotauro. JL Jornal de Letras, Artes e Ideias. Consultado em: https://visao.sapo.pt/jornaldeletras/ideiasj1/2020-06-03-quando-teseu-se-rendeu-aominotauro/.

Žižek, Slavoj. (2020). A Pandemia que Abalou o Mundo. Lisboa: Relógio d’Água. 